PACS 07.20.Mc, 65.60+a, 75.30.Hx, 78.30.Ly, 78.55.Qr

\title{
Photoluminescence of $\mathrm{As}_{2} \mathrm{~S}_{3}$ doped with $\mathrm{Cr}$ and $\mathrm{Yb}$
}

\author{
A.V. Stronski ${ }^{1}$, O.P. Paiuk ${ }^{1}$, V.V. Strelchuk ${ }^{1}$, Iu.M. Nasieka ${ }^{1}$, M. Vlček ${ }^{2}$ \\ ${ }^{I} V$. Lashkaryov Institute of Semiconductor Physics, NAS of Ukraine, \\ 41, prospect Nauky, 03028 Kyiv, Ukraine \\ ${ }^{2}$ University of Pardubice, Faculty of Chemical Technology, Pardubice, Czech Republic
}

\begin{abstract}
The results of experimental researches of photoluminescence spectra in $\mathrm{As}_{2} \mathrm{~S}_{3}$ glasses obtained by doping of $\mathrm{Cr}$ and $\mathrm{Yb}$ ions to As-S host matrix followed by Raman and calorimetric studies as well as low-temperature magnetization measurements have been given. Possible mechanisms of obtained effects are discussed.
\end{abstract}

Keywords: chalcogenide glass, photoluminescence, Raman spectra, thermal property, magnetization.

Manuscript received 07.02.14; revised version received 25.06.14; accepted for publication 29.10.14; published online 10.11.14.

\section{Introduction}

Chalcogenide glasses (ChGs) exhibit a number of interesting optical properties with various potential applications as reviewed in, for example [1,2], etc. As frequently pointed out by various researchers, ChGs are promising materials for various applications because they are transparent over a wide range of wavelengths in the infrared region, they possess high refractive indices, low phonon energies and are easy to fabricate. Chalcogenide glasses can be used in applications in sensorics, infrared optics and optoelectronics. The glasses can be used for preparation of optical fibers both for passive and active applications.

The refractive index and its wavelength dependence, luminescent properties are among important parameters that determine the suitability of materials as optical media. The photoluminescence (PL) spectrum of arsenic chalcogenides when excited by light with $\hbar \omega \approx E_{g}$ ( $E_{g}$ is an optical bandgap energy) lies at about half the optical gap, which means that PL undergoes a strong Stokes shift, and it appears as a broad Gaussianshaped spectrum with a peak energy $E_{P L}$ approximately at $E_{P L} \approx E_{g} / 2$ [3-5]. Developments in photonics applications highlighted the chalcogenide glass as a host for rare-earth ions [1, 6-9].
Tanaka [10] proposed a new model for the half-gap PL. The latter arises from recombination of electrons, being trapped by anti-bonding states of wrong (and strained) bonds at around the mid-gap Fermi level, and holes in Urbach-edge states at the valence-band top. The wrong bond seems to be the most dominant defect in covalent chalcogenide semiconductors such as $\mathrm{As}_{2} \mathrm{~S}(\mathrm{Se})_{3}$, irrespective of glass and crystal, and accordingly, this model can be applied to the corresponding crystals as well. The PL fatigue, which is more prominent in the glass, may arise from momentary trapped electrons (type I) and broken chemical bonds (type II) in disordered flexible lattices. However, complete understandings of the PL fatigue remain difficult as caused by some experimental limitations.

In this work, photoluminescence of $\mathrm{As}_{2} \mathrm{~S}_{3}$ doped with $\mathrm{Cr}$ and $\mathrm{Yb}$ was investigated.

\section{Experimental}

The glasses of compositions $\mathrm{As}_{2} \mathrm{~S}_{3}, \mathrm{As}_{2} \mathrm{~S}_{3}: \mathrm{Cr} 0.5$ wt.\% and $\mathrm{As}_{2} \mathrm{~S}_{3}: \mathrm{Cr} 0.75$ wt.\%, $\mathrm{As}_{2} \mathrm{~S}_{3}, \mathrm{As}_{2} \mathrm{~S}_{3}: \mathrm{Yb} 0.5$ wt.\%, $\mathrm{As}_{2} \mathrm{~S}_{3}: \mathrm{Yb} 1$ wt.\% and $\mathrm{As}_{2} \mathrm{~S}_{3}: \mathrm{Yb} 2$ wt.\% were prepared using the standard melt-quenching technique with constituent elements of $6 \mathrm{~N}$ purity, which were melted in vacuum-sealed silica ampoules for $10 \ldots 12$ hours and 
subsequently quenched in air. Room temperature Raman spectra were recorded using a Fourier spectrophotometer Bruker IFS-55 Equinox with FRA-106 attachment.

Photoluminescence of $\mathrm{As}_{2} \mathrm{~S}_{3}$ doped with $\mathrm{Cr}$ was studied within the $800 \ldots 1600-\mathrm{nm}$ region $\left(T=77 \mathrm{~K}, \lambda_{e x}=\right.$ $514 \mathrm{~nm}$ ) using a HORIBA Jobin-Yvon T64000 spectrometer. Photoluminescence of As-S glasses modified with $\mathrm{Yb}$ was excited by a laser diode at the 980-nm wavelength with the radiation intensity $150 \mathrm{~mW}$ and was registered at room temperature using a Zolix SBP 300 monochromator (resolution $\sim 1 \mathrm{~nm}$ ) with Zolix CR131 attachment.

Thermal properties were studied using the DSC technique, $T_{g}$ values for undoped and doped glasses were obtained. NETZSCH DSC 404 calorimeter (with accuracy $\pm 0.5 \mathrm{~K}$ ) was used in DSC measurements. Calorimetric measurements were carried out using powder samples $(m \sim 20 \mathrm{mG})$ in argon atmosphere under temperature changes within $40 \ldots 250^{\circ} \mathrm{C}$. The heating rate $q=10 \mathrm{~K} / \mathrm{min}$. Calibration of the calorimeter was carried out by melting pure metals $\mathrm{In}, \mathrm{Sn}, \mathrm{Bi}, \mathrm{Pb}, \mathrm{Al}, \mathrm{Cu}$ with known values of temperature and enthalpy of melting.

Magnetization of the samples was measured with a Cryogenic S600 Super-conducting Quantum Interference Device (SQUID) magnetometer within the temperature range $5 \ldots 400 \mathrm{~K}$ and in magnetic fields up to $5 \mathrm{~T}$. A cryogenic system was completed with automated instrument control, data acquisition and analysis using the National Instrument's LabVIEW software.

\section{Results}

\section{Raman spectra}

Introduction of $\mathrm{Cr}$ impurity (Fig. 1) leads to the intensity increase of the bands at 192, 227, 236, 365 $\mathrm{cm}^{-1}$, which correspond to the presence of non-stoichiometric molecular fragments of the $\mathrm{As}_{4} \mathrm{~S}_{4}$ nanophase. The intensity of the $496-\mathrm{cm}^{-1}$ band, characteristic for the vibrations of S-S bonds, is decreased with the $\mathrm{Cr}$ introduction. The difference spectra (Fig. 2) reveal the changes occurred in the glass structure upon variation of composition. From these spectra, one can be see that addition of $\mathrm{Cr}$ leads to intensity increase of the $150-\mathrm{cm}^{-1}$ band that corresponds to vibrations of phasedecomposed $\mathrm{S}_{8}$ rings and the $317-\mathrm{cm}^{-1}$ band, which can be attributed to pyramidal structural $\mathrm{AsS}_{3}$ units with additional sulfur atoms involved into (-S-S-) chains and joined pyramidal fragments. The main observed effect under introduction of chromium into $\mathrm{As}_{2} \mathrm{~S}_{3}$ is the change of the relative concentration of the main and nonstoichiometric structural units characteristic for $\mathrm{As}_{2} \mathrm{~S}_{3}$ glasses.

Chalcogenide glasses $\mathrm{As}_{2} \mathrm{~S}_{3}$ doped with ytterbium were investigated using Raman spectroscopy to obtain information regarding incorporation of impurity metal ions into the host glass structure. Introduction of $\mathrm{Yb}$ leads (Figs 3a and 3b) to the intensity increase of the bands at $192,227,236,365 \mathrm{~cm}^{-1}$ that correspond to the presence of the $\mathrm{As}_{4} \mathrm{~S}_{4}$ nanophase. The intensity of the $496 \mathrm{~cm}^{-1}$ band characteristic for the vibrations of S-S bonds is decreased with the $\mathrm{Yb}$ introduction. The difference spectra reveal changes occurred in the glass structure upon variation of composition. From these spectra, it can be seen that addition of $\mathrm{Yb}$ leads to the intensity increase in the $150-\mathrm{cm}^{-1}$ band that corresponds to vibrations of phase-decomposed $\mathrm{S}_{8}$ rings and the $317-\mathrm{cm}^{-1}$ band, which can be attributed to pyramidal structural $\mathrm{AsS}_{3}$ units with additional sulfur atoms involved into (-S-S-) chains and joined pyramidal fragments. Doping of $\mathrm{As}_{2} \mathrm{~S}_{3}$ glasses with small amount of $\mathrm{Yb}$ ions, up to $1 \mathrm{wt} . \%$, only slightly affect the shortrange order structure of the host matrix. The main observed effect after introduction of ytterbium into $\mathrm{As}_{2} \mathrm{~S}_{3}$ is the change of the relative concentration of the main and non-stoichiometric structural units characteristic for $\mathrm{As}_{2} \mathrm{~S}_{3}$ glasses.

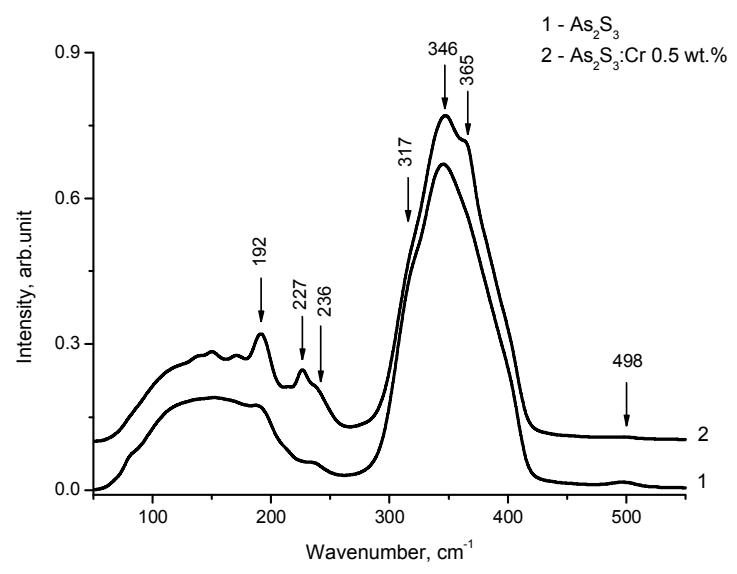

Fig. 1. Raman spectra of $\mathrm{As}_{2} \mathrm{~S}_{3}$ and $\mathrm{As}_{2} \mathrm{~S}_{3}$ :Cr 0.5 wt.\%.

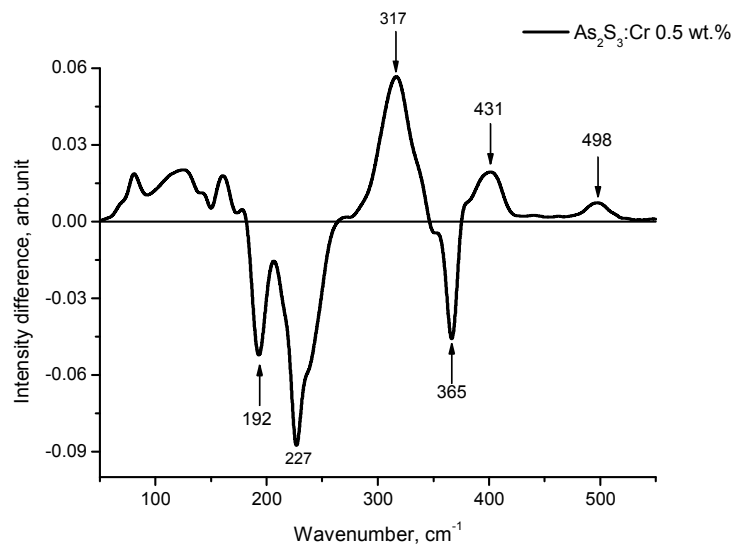

Fig. 2. Differential Raman spectra of $\mathrm{As}_{2} \mathrm{~S}_{3}$ doped with $\mathrm{Cr}$ 0.5 wt.\% (relatively to $\mathrm{As}_{2} \mathrm{~S}_{3}$ ). 


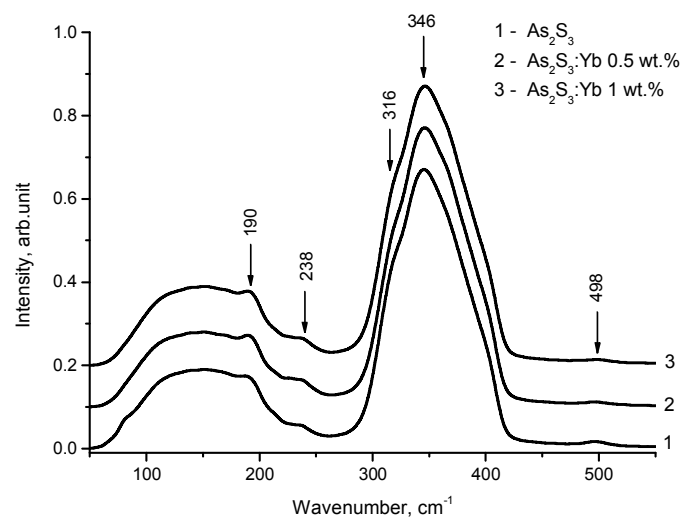

Fig. 3a. Raman spectra of $\mathrm{As}_{2} \mathrm{~S}_{3}, \mathrm{As}_{2} \mathrm{~S}_{3}: \mathrm{Yb} 0.5 \mathrm{wt} \%$ and $\mathrm{As}_{2} \mathrm{~S}_{3}: \mathrm{Yb} 1 \mathrm{wt} . \%$. Spectra are normalized by intensity of the $346 \mathrm{~cm}^{-1}$ peak and shifted by equal distances in order of appearance.

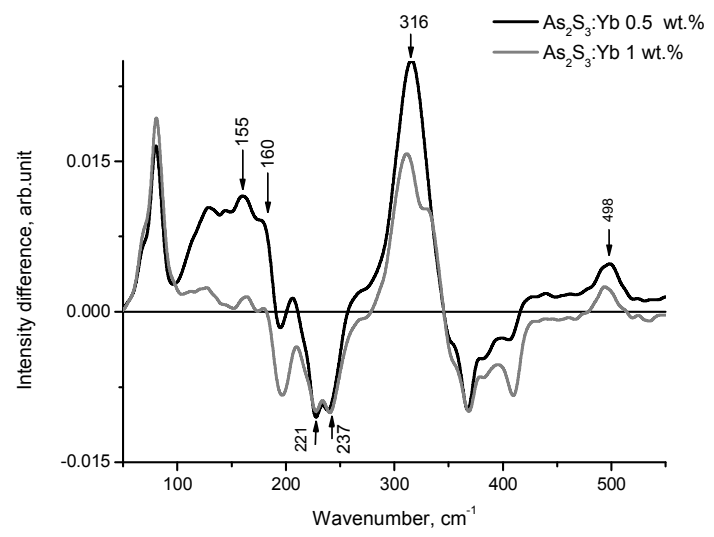

Fig. 3b. Difference Raman spectra of chalcogenide glasses: $\mathrm{As}_{2} \mathrm{~S}_{3}: \mathrm{Yb} 0.5$ wt. $\%$ and $\mathrm{As}_{2} \mathrm{~S}_{3}+\mathrm{Yb} 1$ wt.\% (relatively to $\mathrm{As}_{2} \mathrm{~S}_{3}$ ).

\section{Thermal properties}

Thermogram for As-S:Cr with $\mathrm{Cr}$ content 0.75 wt.\% (heating rate $10 \mathrm{~K} / \mathrm{min}$ ) is shown in Fig. 4. It is necessary to note that with increase of the heating rate, $T_{g}$ value is shifted towards higher temperatures. Kissinger's expression was used for estimating the activation energy of glass transition. The obtained $T_{g}$ values for $\mathrm{As}_{2} \mathrm{~S}_{3}$ with various concentrations of $\mathrm{Cr}$ and $\mathrm{Yb}$ are presented in Table.

Table. Glass transition temperature $T_{g}$ of doped As-S glasses $(q=10 \mathrm{~K} / \mathrm{min})$.

\begin{tabular}{|l|c|}
\hline \multicolumn{1}{|c|}{ Composition } & $T_{g},{ }^{\circ} \mathrm{C}$ \\
\hline $\mathrm{As}_{2} \mathrm{~S}_{3}$ & 208.3 \\
\hline $\mathrm{As}_{2} \mathrm{~S}_{3}: \mathrm{Cr} 0.5$ wt. $\%$ & 204.5 \\
\hline $\mathrm{As}_{2} \mathrm{~S}_{3}: \mathrm{Cr} 0.75$ wt.\% & 202.8 \\
\hline $\mathrm{As}_{2} \mathrm{~S}_{3}: \mathrm{Yb} \mathrm{0.5} \mathrm{wt. \%}$ & 207 \\
\hline $\mathrm{As}_{2} \mathrm{~S}_{3}: \mathrm{Yb} 1$ wt. $\%$ & 206.2 \\
\hline
\end{tabular}

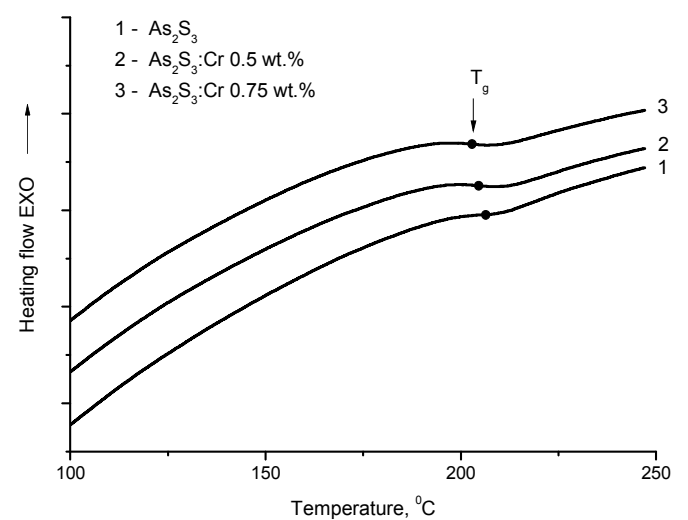

Fig. 4a. Thermograms of As-S:Cr glass with $\mathrm{Cr}$ content $0,0.5$ and $0.75 \mathrm{wt} . \%$ at the heating rate $10 \mathrm{~K} / \mathrm{min}$.

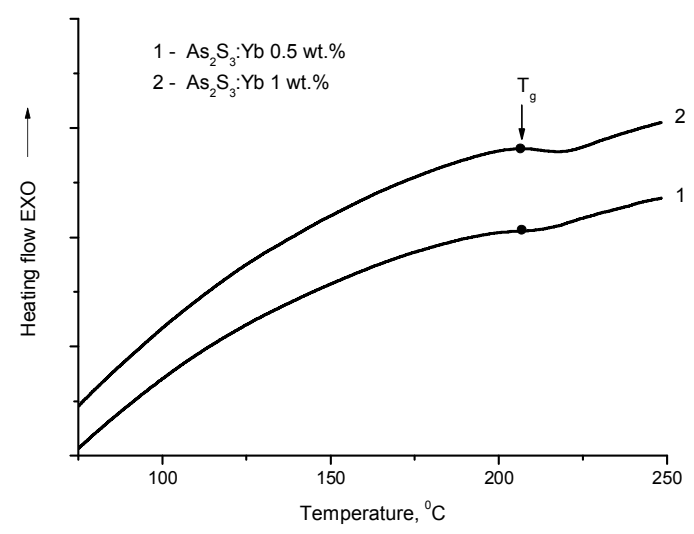

Fig. 4b. Thermograms of $\mathrm{As}_{2} \mathrm{~S}_{3}$ with content of $\mathrm{Yb} 0.5$ wt.\% and $1 \mathrm{wt} . \%$ at the heating rate $10 \mathrm{~K} / \mathrm{min}$.

\section{Luminescence}

Photoluminescence spectra for glasses $\mathrm{As}_{2} \mathrm{~S}_{3}: \mathrm{Cr}$ with different $\mathrm{Cr}$ composition are presented in Fig. 5. It can be seen from the figure that the photoluminescence intensity increases with the $\mathrm{Cr}$ concentration, thus, showing the increased level of defects with the chromium introduction having small effect on its shape.

Rare-earth luminescence As-S glasses modified by $\mathrm{Yb}$ have two luminescence bands in the near IR range, which are placed near 980 and $1060 \mathrm{~nm}$ (Fig. 6). In this case, transitions from the excited state ${ }^{2} \mathrm{~F}_{5 / 2}$ to the main state ${ }^{2} \mathrm{~F}_{7 / 2}$ that are characteristic for ion $\mathrm{Yb}^{3+}$ are pronounced. The intensity of photoluminescence increases with increase of the ytterbium concentration.

\section{Magnetic properties}

Pure chalcogenide glasses are diamagnetics. Introduction of transitional and rare earth impurities changes magnetic properties of the investigated chalcogenide glasses [13]. In the fields near $5 \mathrm{~T}$, the $M(T)$ dependence was observed (Fig. 7), which is characteristic for paramagnetics and ferromagnetics in the paramagnetic temperature range 
[13]. Measurements of magnetic properties (temperature dependence of the specific magnetic moment) were performed under various conditions of sample cooling. A sample was cooled in zero external magnetic field, then the magnetic field with specified magnitude was set. In what follows, this magnetic field was maintained constant during the sample heating. The interval of temperature variation was chosen in such a way that the maximal value of temperature exceeded the temperature of transition into the paramagnetic state. Hereinafter, such dependences are denoted as ZFC. Further, the sample was cooled in the magnetic field and $M=M(T)$ was obtained. It is denoted as FC in figures.

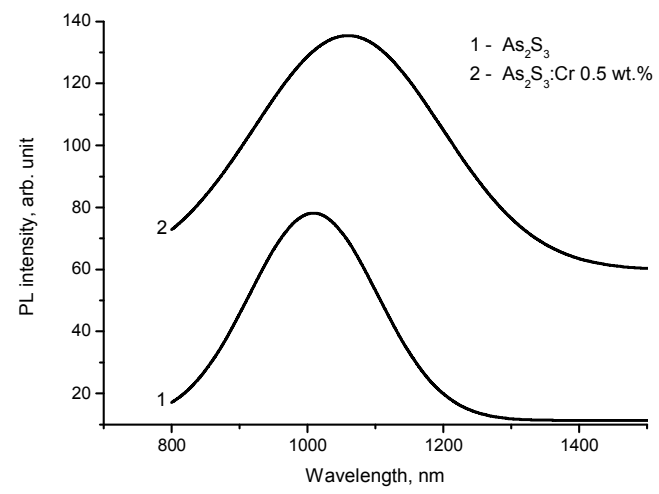

Fig. 5. Luminescence spectra of undoped $\mathrm{As}_{2} \mathrm{~S}_{3}$ and doped with $\mathrm{Cr} 0.5$ wt.\%.

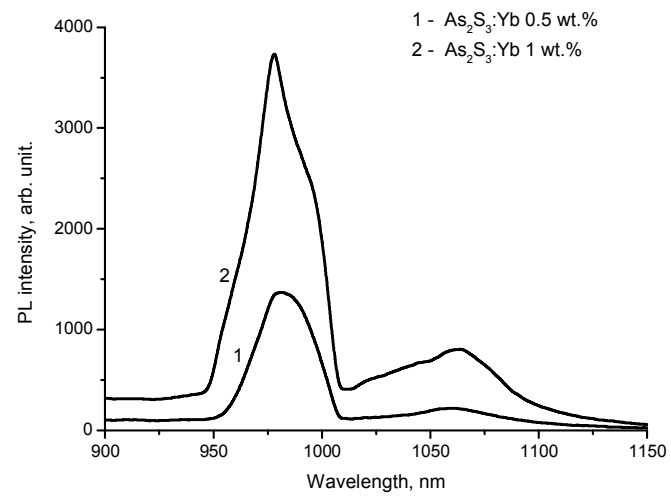

Fig. 6. Luminescence spectra of $\mathrm{As}_{2} \mathrm{~S}_{3}$ doped with $\mathrm{Yb}: 0.5$ and 1 wt.\%.

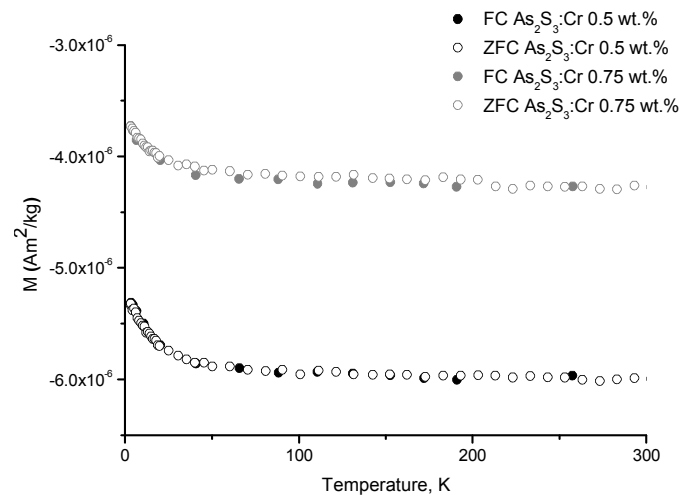

Fig. 7. Temperature dependence of mass magnetization $(M)$ in $\mathrm{As}_{2} \mathrm{~S}_{3}$ doped with $\mathrm{Cr} 0.5$ and 1 wt.\% $(B=5 \mathrm{~T})$.

\section{Discussion}

Results on photoluminescence spectra for glasses $\mathrm{As}_{2} \mathrm{~S}_{3}$ : $\mathrm{Cr}$ with different $\mathrm{Cr}$ content are in agreement with the model proposed by Tanaka [10]. According to Tanaka's model, half-gap photoluminescence arises from recombination of electrons, being trapped by anti-bonding states of wrong (and strained) bonds at around the midgap Fermi level, and holes in Urbach-edge states at the valence-band top. The wrong bonds are considered as the most dominant defects in covalent chalcogenide semiconductors such as $\mathrm{As}_{2} \mathrm{~S}(\mathrm{Se})_{3}$. The wrong-bond density in $\mathrm{As}_{2} \mathrm{~S}_{3}$ is markedly affected by the preparation condition [11]. Also, it is necessary to note that the density of the wrong bond in $\mathrm{As}_{2} \mathrm{~S}(\mathrm{Se})_{3}$ is estimated at a few atomic percent, which is consistent with the insensity of photoluminescence on impurity concentrations up to $\sim 0.1$ at. $\%$. At this level, the wrong bond concentration change can be tracked by Raman spectroscopy as was shown above. Raman measurements show that the intensity of bands that correspond to the presence of $\mathrm{As}_{4} \mathrm{~S}_{4}$ nanophase is increased with the growth of the $\mathrm{Cr}$ concentration, that is, the number of the wrong As-As bonds is increased. And due to increase of the number (concentration) of the wrong As-As, the luminescence intensity must be increased, which can be seen in Fig. 5 .

Developments in photonics applications of chalcogenide glasses have highlighted them as a matrixhost for rare-earth ions [7-9]. Bishop et al. [12] demonstrated the so-called broad-band excitation, i.e., excitation of rare-earth ions, not directly, but through exciting the host chalcogenide glass having a broad Urbach-edge spectrum. Chalcogenide glasses can be doped by significant amounts of impurities (up to the level of several atomic percents) without essential changing the optical quality [14]. This feature can be connected with the flexibility of the glass network, lesser density of glass as compared to the crystal, presence of nanovoids (which sizes can be estimated from positron annihilation lifetime spectra using different formula $[15,16])$. It is necessary to note that introduction of rare earth elements can change not only luminescent but also magnetic properties of chalcogenide glasses.

\section{Conclusions}

Optical, thermal, luminescent and magnetic properties of chalcogenide glasses can be changed by doping of transitional and rare-earth metals. Photoluminescence of $\mathrm{As}_{2} \mathrm{~S}_{3}$ doped with $\mathrm{Cr}$ is well explained by the model proposed by Tanaka [10]. Chalcogenide glasses can be host for rare-earth metals, which provides a possibility to simultaneously change both luminescent and magnetic properties of glasses.

\section{Acknowledgements}

The research was supported by the project FP-7 SECURE-R21. 
References

1. I.D. Aggarwal, J.S. Sanghera, Development and applications of chalcogenide glass optical fibers at NRL // Journal of Optoelectronics and Advanced Materials, 4(3), p. 665-678 (2002).

2. A.V. Stronski, M. Vlček, Photosensitive properties of chalcogenide vitreous semiconductors in diffractive and holographic technologies applications // Journal of Optoelectronics and Advanced Materials, 4(3), p. 699-704 (2002).

3. Amorphous Semiconductors, Topics in Applied Physics, v.36, Eds. M.H. Brodsky, p. 176-185, Springer-Verlag, Berlin, 1979.

4. N.F. Mott and E.A. Davis, Electron Processes in Non-crystalline Materials. Clarendon press, Oxford, p. 583, 1979.

5. A. Feltz, Amorphous Inorganic Materials and Glasses. VCH, Weinheim, Germany, p. 446, 1993.

6. A.B. Seddon, Z. Tang, D. Furniss, S. Sujecki and T.M. Benson, Progress in rare-earth-doped midinfrared fiber lasers // Opt. Exp. 18(25), p. 2670426719 (2010).

7. D. Lezal, Chalcogenide glasses - survey and progress // Journal of Optoelectronics and Advanced Materials, 5(1), p. 23-34 (2003).

8. S.O. Kasap, K. Koughia, M. Munzar, D. Tonchev, D. Saitou, T. Aoki, Recent photoluminescence research on chalcogenide glasses for photonics applications // J. Non-Cryst. Solids, 353, p. $1364-$ 1371 (2007).
9. K. Tanaka, K. Shimakawa, Amorphous Chalcogenide Semiconductors and Related Materials. Springer, New York, 2011.

10. K. Tanaka, Photoluminescence in chalcogenide glasses: revisited // Journal of Optoelectronics and Advanced Materials, 15(11-12), p. 1165-1178 (2013).

11. K. Tanaka, The charged defect exists? // Journal of Optoelectronics and Advanced Materials, 3(2), p. 189-198 (2001).

12. G. Bishop, D.A. Turnbull, and B.G. Aitken, Excitation of rare earth emission in chalcogenide glasses by the broadband Urbach edge absorption // J. Non-Cryst. Solids 266-269, p. 876-883 (2000).

13. A. Gubanova, Ts. Kryskov, A. Paiuk et al., Some magnetic properties of chalcogenide glasses $\mathrm{As}_{2} \mathrm{~S}_{3}$ and $\mathrm{As}_{2} \mathrm{Se}_{3}$ doped with $\mathrm{Cr}, \mathrm{Mn}$ and $\mathrm{Yb} / /$ Moldavian J. Phys. Sci. 8(2), p. 178-185 (2009).

14. A.V. Stronski, M. Vlček, A.I. Stetsun, A. Sklenař, P.E. Shepeliavyi, Raman spectra of Ag- and $\mathrm{Cu}-$ photodoped $\mathrm{As}_{40} \mathrm{~S}_{60-\mathrm{x}} \mathrm{Se}_{\mathrm{x}}$ films // J. Non-Cryst. Solids, 270, p. 129-136 (2000).

15. A. Stronski, Positron annihilation lifetime spectroscopy measurement of $\mathrm{Ge}_{5} \mathrm{As}_{37} \mathrm{~S}_{58}$ glass // Adv. Mater. Res. 854, p. 111-115 (2014).

16. O.I. Shpotyuk, M.M. Vakiv, M.V. Shpotyuk, A. Ingram, J. Filipecki, A.P. Vaskiv, Free-volume correlations in positron-sensitive annihilation modes in chalcogenide vitreous semiconductors: on the path from illusions towards realistic physical description // Semiconductor Physics, Quantum \& Optoelectronics, 17(3), p. 243-251 (2014). 